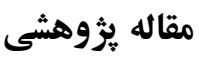

مجله دانشگَاه علوم يزشكى رفسنجان

دوره 19، خرداد

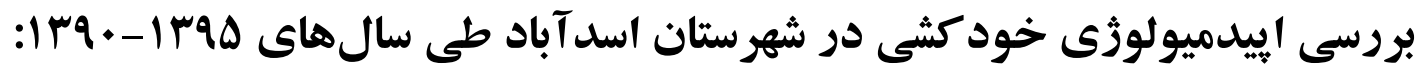
يكى مطالعه توصيفى

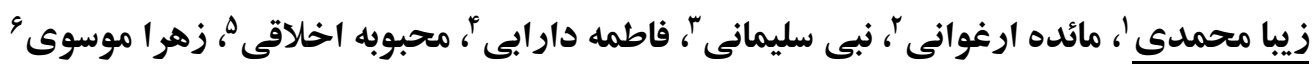

هذيرش مقاله: 99/r/T

دريافت اصلاحيه از نويسنده:

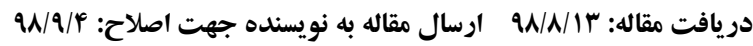

جكيده

زمينه و هدف: خودكشى يكى از بزركترين مشكلات يزشكى و اجتماعى جهان است. مطالعه حاضر با هدف تعيين

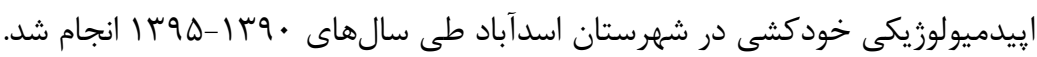
مواد و روشها: در اين مطالعه توصيفى، اطلاعات دموكرافيك و إيبدميولوزيك موارد اقدام به خودكشى و خودكشى كامل طى سلى

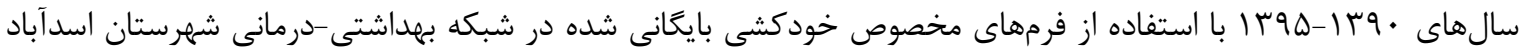
استخراج شد. دادها با استفاده از آمار توصيفى مورد تجزيه و تحليل قرار گرفتند.

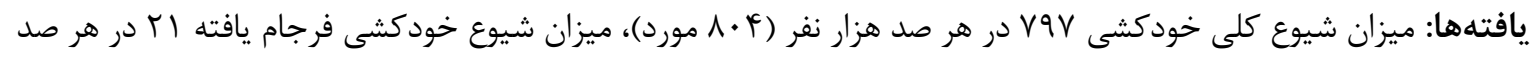

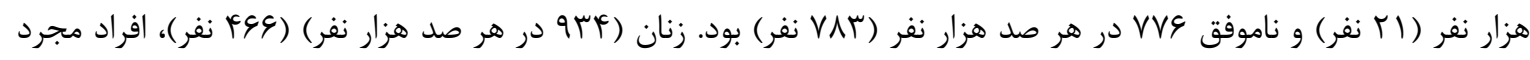

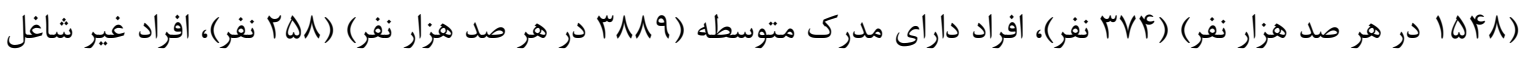

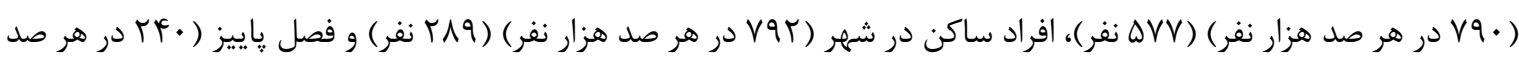

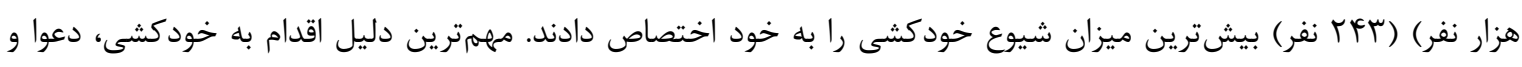

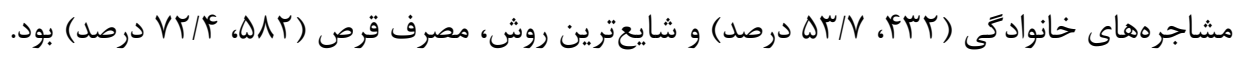

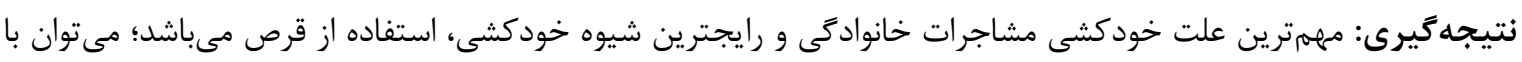

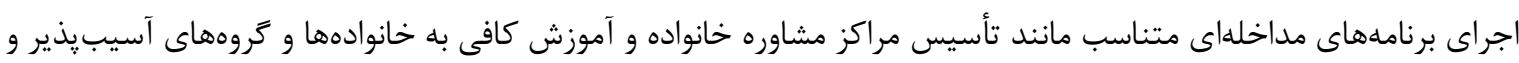
همرجنين با كاهش دسترسى به وسايل خودكشى در جهت كاهش ميزان شيوع خودكشى كام برداشت. وازههاى كليدى: إيدميولوزى، اقدام به خودكشى، شهرستان اسدآباد

ا- (نويسنده مسئول) مربى كروه آموزشى يرستارى، دانشخاه علوم يزشكى همدان، همدان، ايران. دانشكده علوم يزشكى اسداباد، اسداباد، ايران

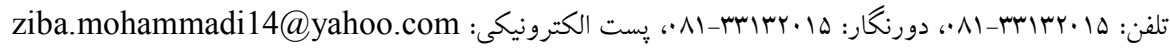

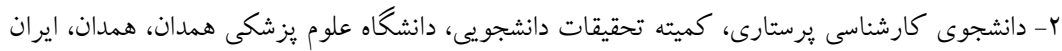

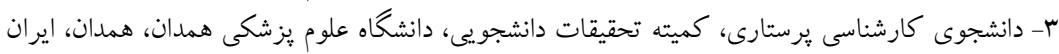

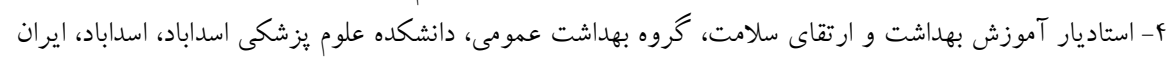

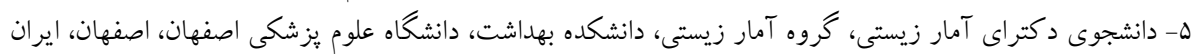

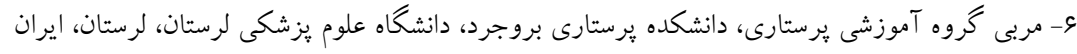


بسته به وضعيت جغرافيايى در كشورها و مناطق مختلف

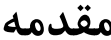
متفاوت مىباشد؛ بهطورى كه V9 درصد خودكشىهاى جهان در كشورهاى با درآمد يايين و متوسط رخ مىدهد [ع]. ميزان خودكشى طى سالهاى اخير در ايران افزايش يافته است و به رقم \&/9 در صد هزار نفر جمعيت رسيده است [1]. از نظر رتبه جهانى خودكشى، ايران در رتبه ه ه ام قرار دارد كه در اين ميان سه استان ايلام، كرمانشاه و همدان بالاترين آمار خودكشى را دارند [بّ]. Daliri و همكاران طى مطالعهاى بيان داشتند كه ميزان بروز خودكشى طى سالهاى اخير در ايران روند كاهشى داشته است؛ در حالى كه استانهاى غربى كشور بروز نسبتا بالايى داشتند. بيشترين ميزان بروز خودكشى فرجام يافته در كشور مربوط به منطقه اقليمى يك (ايلام، لرستان، همدان، كردستان و كرمانشاه) بود. همرجنين منطقه اقليمى ه (اصفهان، يزد، سمنان و قم) داراى بيشترين ميزان برز اقدام به خودكشى و كمترين ميزان بروز خودكشى فرجام يافته بود [11]. از عوامل مهم زمينهساز خودكشى مىتوان به بيمارىهاى جسمى مستعد كننده (صرع، ايدز، سرطان و ...)، اختلالات روانى (افسردگى، اختلال شخصيت، سوء مصرف مواد مخدر و الكل، سوء استفاده جنسى)، عوامل دموكرافيك (وضعيت تأهل، سن، جنسيت، مذهب، نزاد)، عوامل اقتصادى (فقر، بيكارى، ورشكستگى و ...)، عوامل محيطى (زمان، مكان يا در دسترس بودن وسيله خودكشى)، يناهندكى و مهاجرت، مشكلات عاطفى - ارتباطى (انزواى اجتماعى، خشونت)، زندان و مشكلات خانوادگى اشاره كرد [9، IV-IV]

يكى از بزركترين مشكلات يزشكى و اجتماعى جهان و اورزانس اصلى در مباحث روانيزشكى، معضل خودكشى است [Y-I]. بر اساس تعريف سازمان بهداشت جهانى Word) اقدام به خودكشى عبارت از عملى Health Organization) است كه در آن شخص عمدى و بدون مداخله ديخران رفتارى غيرعادى مثل خود آسيبزنى يا خوردن يك ماده به ميزان بيشتر از مقدار تجويز شده براى درمان را انجام دهد و هدف وى تحقق تغييرات مورد انتظار خود است [ए]. ايده خودكشى معمولاً محدوده اى از ايدههاى نسبتاً منفعل (مثلاً ميل داشتن به مردن) تا ايدههاى فعال (از جمله تمايل براى كشتن خود يا تفكر به يك روش خاص درباره اينكه جطور آن را انجام دهد) را شامل مى شود [^][. خودكشى دهمين علت مرك در دنيا و هشتمين علت مرى و مير در ايالت متحده آمريكا است

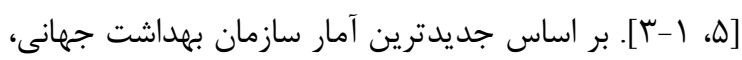
هر سال حدود . ... . ن نفر بر اثر خودكشى در سراسر جهان مىميرند [9]. طبق كزارش اين سازمان آمار خودكشى در جهان رو به افزايش است؛ بهطورى كه ميانگَين سالانه جهانى

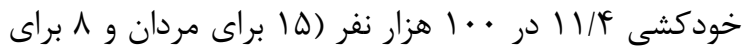

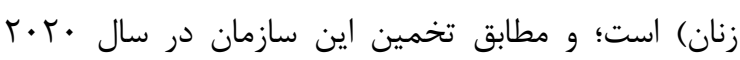
ميلادى تقريباً ..... مها نفر در اثر خودكشى خواهند مرد [V-9] همرجنين به ازاء هر مورد مرك، له مورد اقدام به خودكشى و ميليونها فردى كه افكار خودكشى را تجربه كردهاند، وجود دارد [ • []؛ بلطورى كه در جهان هر سه ثانيه يك اقدام به خودكشى رخ مى دهد [r-1]. فراوانى خودكشى 
إيدميولوزى خودكشى در شهرستان اسداباد همدان طى

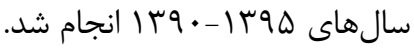

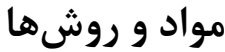

شهرستان اسد آباد در گسترهاى به مساحت 9911 أكيلومتر مربع و با 19.9.1 نفر جمعيت، آخرين شهرستان غربى همدان است. اين شهرستان براساس تقسيمات كشورى، داراى دو نقطه شهرى به نامهاى اسدآباد و آجين و 99 روستاى داراى سكنه است. كل جمعيت آن بر اساس آخرين سرشمارى مركز آمار ايران در سال هو؟1، 1.9... نفر بوده است

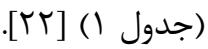
در مطالعه توصيفى حاضر، تمام موارد خودكشى و اقدام به آن در شهرستان اسدآباد طى سالهاى هوبا-•وبا كه به واحدهاى بهداشتى درمانى (اورزانس بيمارستانهاى قائم (عج) و امير المؤمنين (ع)) ارجاع شده بودند، به صورت سرشمارى مورد بررسى قرار ترفتند. در اين مطالعه، اطلاعات از يرونده هاى بيماران به دست آمده است. جهت يِيشخيرى از كمبرآوردى شيوع كلى، فرمهاى ناقص نيز در مطالعه وارد شدند. لذا عدم اطلاع از دقت و صحت جمع آورى دادهها و ثبت آنها در فرمهاى مخصوص خودكشى و عدم دسترسى به كل نمونهها به دليل ثبت نشدن يا مراجعه نكردن فرد به اين مراكز درمانى از محدوديتهاى مطالعه حاضر مىباشد. جهت جمعآورى اطلاعات از فرم مخصوص خودكشى (فرم كزارش موارد اقدام به خودكشى و موارد مركى و مير ناشى از آن) كه توسط معاونت بهداشتى - درمانى دانشخاه علوم يزشكى همدان در اختيار مراكز بهداشتى درمانى قرار كرفته بود و يس

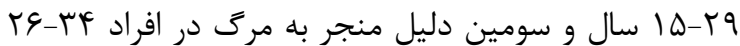
سال در جهان است [4 (1، 9، 9]. سازمان بهداشت جهانى نيز ارتكاب قبلى خودكشى را به عنوان مهمترين عامل خطر براى خودكشى در عموم جمعيت بيان كرده است [؟]. تخمين زده مىشود كه حدود · آ درصد از خود كشىهاى جهان به علت مسموميت با آفت كشهاست كه اكثر آنها در مناطق كشاورزى روستايى در كشورهاى كم درآمد و با درآمد متوسط رخ مىدهد [؟]. در ايران قديم خودكشى با خوردن ترياك ديده شده است و امروزه مردان بيشتر از شيوههاى خوردن قرص، حلق آويز كردن، سلاح كرم و زنان بيشتر از خودسوزى استفاده مى كنند [9 1911]. عمدهترين تأثيراتى كه خودكشى در يك جامعه بر جاى مى كذارد عبارتند از آسيب زدن به بهداشت روانى خانواده و جامعه، از بين بردن نيروى فعال و مولد جامعه، به جاى كذاشتن تأثيرات سوء بر فضاى اجتماعى، كاهش امنيت و اعتماد اجتماعى، افزايش احتمال و وقوع خودكشى در ساير افراد جامعه و ايجاد نوعى فضاى يأس و ناميدى در جامعه مىباشند [·r]]. بنابر اين با در نظر كرفتن موارد بروز و شيوع بالاى خودكشى و با توجه به اين مسئله كه به ازاى هر مورد خودكشى يا اقدام به خودكشى، حداقل ينج نفر از دوستان، آشنايان و اقوام فرد به طور جدى تحت تأثير اين حادثه قرار مى مرتبط با اين آسيب اجتماعى جهت پِيشَيرى و كنترل آن ضرورى به نظر مىرسد. لذا در اين راستا و با عنايت به اين كه استان همدان يكى از استانهايى است كه بالاترين آمار خودكشى را دارد [ [1 1]، بنابر اين يزوهش حاضر با هدف تعيين 
1 אץ بررسى إيبدميولوزى خودكثى در شهرستان اسدآباد

جمع آورى اطلاعات، دادهها با استفاده از آمارههاى توصيفى (فراوانى، ميانگين و انحراف معيار)، نمودارها و جداول آمارى، آزمونهاى كاى دو و آزمون دقيق فيشر، توصيف شدند. براى تحليل دادهها از نرم افزار SPSS نسخه ع Y استفاده شد.

\section{نتايج}

بر اساس اطلاعات استخراج شده از يروندهها در شهرستان

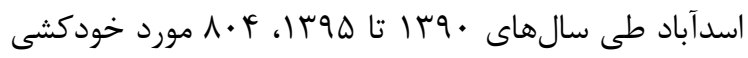
صورت كرفته بود و اين نشان دهنده ميزان شيوع كلى خودكشى Vq در هر صد هزار نفر در اين شهرستان مى باشد. همرجنين ميزان شيوع خودكشى فرجام يافته (منجر به مرك) ا Y در هر صد هزار نفر (آ نفر) و ناموفق VVY در هر صد

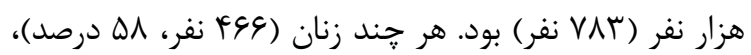

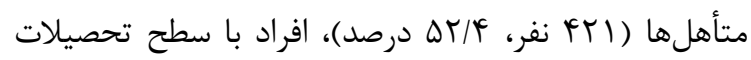

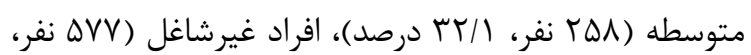
VI/V درصد) و افراد شهرنشين (rاع نفر، QV/ درصد) اكثريت افراد اقدام كننده به خودكشى را تشكيل دادند، اما ميزان شيوع خودكشى در زنان (F مجرد (WFA ا در هر صد هزار نفر)، افراد داراى مدرك متوسطه

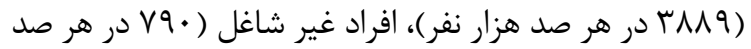
هزار نفر) و افراد ساكن در شهر (Y VI در هر صد هزار نفر) بيشتر بود (جدول ().) - (ب)
از تكميل مجدداً به معاونت فوق ارجاع داده مىشد، استفاده شد. همرجنين يك نسخه از هر فرم تكميل شده در واحد حراست شبكه بهداشت شهرستان اسدآباد بايخانى مىشد. اطلاعات اين فرم در دو بخش كلى اطلاعات دموَرافيك (جنس، سن، وضعيت تأهل، ميزان تحصيلات، شغل، محل سكونت) و اطلاعات مربوط به خودكشى و اقدام به آن (سابقه اقدام به خودكشى، سابقه بيمارى روانى، تاريخ اقدام به خودكشى، روش و شيوه خودكشى، علل و انگَيزه خودكشى و

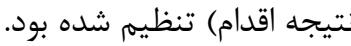
يس إز اخذ مجوز و اخذ كد اخلاق به شماره IR.UMSHA.REC.1396.3 از دانشكاه علوم يزشكى همدان و كسب مجوز از معاونت يزوهشى به شبكه بهداشتى ـ درمانى شهرستان اسدآباد ضمن كسب اجازه از مسئولين و رعايت اصل راز دارى و محرمانه ماندن اطلاعات بيماران، فرمهاى خودكشى بايعانى شده طى سالهاى لهوبا-•وبا توسط

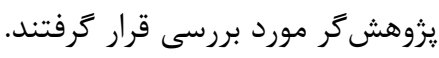
با توجه به جدول ا، ميزان شيوع خودكشى در هر زير گروه برابر با تعداد خودكشى در آن زيركروه تقسيم بر جمعيت آن زيركروه ضرب در . . . . محاسبه شد. به عنوان مثال ميزان شيوع خودكشى در مردان برابر با تعداد مردانى كه در يك ناحيه خودكشى كردهاند، تقسيم بر تعداد كل مردان آن ناحيه و سيس ضرب آن در عدد ...... مىباشد. پֶ از 


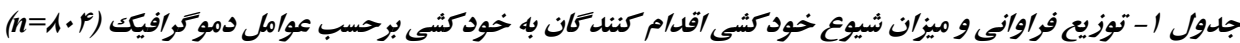

\begin{tabular}{|c|c|c|c|c|c|}
\hline \multirow{2}{*}{ 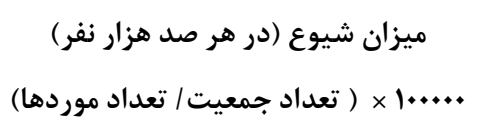 } & \multirow{2}{*}{ شهاعات جمعيتى } & \multicolumn{2}{|c|}{ فراوانى } & \multirow{2}{*}{\multicolumn{2}{|c|}{ متغير }} \\
\hline & & درصد (••|) & تعداد (A+F) & & \\
\hline 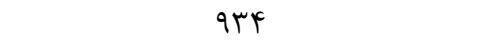 & 4991. & $\Delta \Lambda$ & 199 & 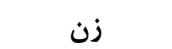 & \\
\hline 991 & 0.991 & $4) / 9$ & vrr & مرد & جنسيت \\
\hline - & - & $\cdot 11$ & 1 & ن ن امعلوم & \\
\hline VVG & DFFE. & $\Delta T / \mathcal{T}$ & FTI & متأهل & \\
\hline $\mid \Delta F \wedge$ & TFIGD & $\varphi \& / \Delta$ & rVt & مجرد & \\
\hline VA & 0.99 & $\cdot 10$ & r & بيوه يا مطلقه & \\
\hline - & rו & $\cdot 19$ & $\Delta$ & ن امعلوم & \\
\hline rel & IGATr & $V / Q$ & 4. & بى سواد & \\
\hline mo & $r V q \cdot \Delta$ & $1 \cdot 19$ & $M \Lambda$ & ابتدايى & \\
\hline $1 \cdots$ & $19 \vee 90$ & $r \cdot / 9$ & 191 & راهنمايى & \\
\hline 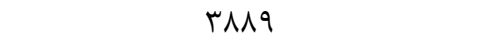 & GQMT & $r T / l$ & $r \Delta \Lambda$ & متوسطه & سطح تحصيلات \\
\hline $1 \cdot 1 \cdot$ & ITYTF & $19 / 4$ & Tr & دييلم & \\
\hline $9 \Delta$. & Q人. & $\Delta / V$ & is & دانشگَاهى & \\
\hline - & IrF & $9 / 0$ & Dr & 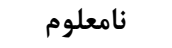 & \\
\hline$\Delta \wedge \varepsilon$ & rVAin & $r \cdot / r$ & 194 & شاغل & \\
\hline vq. & $V \mu \cdot \Lambda r$ & $V I / V$ & $\Delta V V$ & غير شاغل & 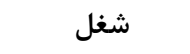 \\
\hline- & & $\Lambda$ & GF & ن امعلوم & \\
\hline Var & $\Delta\langle F F\rangle$ & $\Delta V / \varphi$ & TET & شهر & \\
\hline $9 \wedge \Delta$ & FTIQA & $r \omega / q$ & r^q & روستا & محل سكونت \\
\hline- & $r \cdot r$ & $9 / 0$ & $\Delta T$ & ن امعلوم & \\
\hline
\end{tabular}

درصد) سابقه اختلال روانيزشكى داشتند. بر اساس يافتهها،

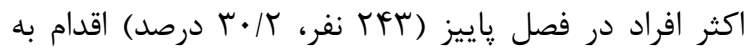

خودكشى كرده بودند (جدول r). ميزان شيوع خودكشى در

فصل بهار • Tr در صد هزار نفر، در فصل تابستان •9 ا در هر

صد هزار نفر، در فصل ياييز·F در هر صد هزار نفر و در
نتايج نشان داد كه بيش از نيمى از افراد (VD/Q V نفر، درصد) اولين تجربه اقدام به خودكشى را داشتند. همجنين در ارتباط با سابقه اختلال روان يزشكى در اقدام كنندكان به خودكشى، درصد كمى از افراد (FV نفر، /A/ درصد) به اين سؤال پِاسخ داده بودند كه از اين تعداد نيز تنها هـ نفر (9/. 
FF. بررسى إيدميولوزى خود كشى در شهرستان اسدآباد

جنين بيشترين و كمترين روشهاى مورد استفاده جهت

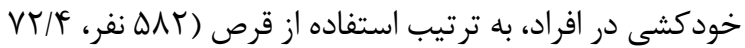
درصد) و خودزنى با اشياء (أl نفر، ال درصد) بودند (جدول

.$(r$
فصل زمستان نيز •ll د در هر صد هزار نفر بود. با توجه به اطلاعات ثبت شده در فرمهاى مخصوص خودكشى، بيشترين انكيزه اقدام به خودكشى به ترتيب دعوا و مشاجره (rrF نفر،

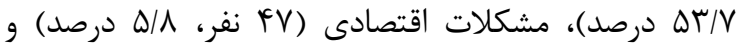
كمترين انخيزه مربوط به اعتياد (ه广 نفر، // درصد) بود. هم

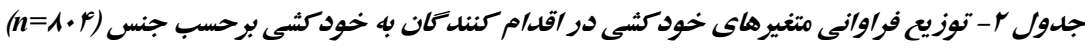

\begin{tabular}{|c|c|c|c|c|c|}
\hline نتايج آزمون & تعداد (درصد) & تعداد (درصد) & 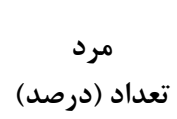 & & متغير \\
\hline \multirow{5}{*}{ 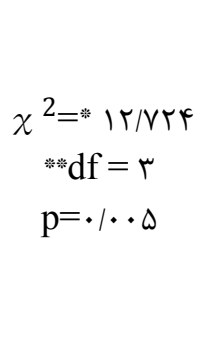 } & $(Y V / Q) T Y F$ & $(r \Delta / \mathcal{L}) \| 1 \wedge$ & $(r \mid / \varphi) 1.9$ & بهار & \multirow{5}{*}{ فصل } \\
\hline & $(T \Gamma / 9) 19$. & $(T V / Q) \mid r \Lambda$ & $(1 \wedge / \Delta) \& r$ & 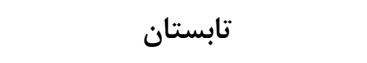 & \\
\hline & $(\Gamma \cdot T) Y \psi r$ & $(\Gamma \mid / \varphi) \mid \uparrow \varphi$ & (५ 9 q & ياييز & \\
\hline & $(I V / V \Lambda) \mid f r$ & $(1 Q / V) V r$ & $(r \cdot / 9) V$. & زمستان & \\
\hline & $(\cdot \mid \Delta T) Y^{C}$ & ---- & --- & بدون ياسخ & \\
\hline \multirow{6}{*}{$\begin{array}{c}\chi^{2}=\varsigma \Delta / \Delta q \varphi \\
\mathrm{df}=\Delta \\
\mathrm{p}<\cdot / \cdot .1\end{array}$} & $(\Delta M / V)$ Frr & $(G Y / T) Y q$. & $(F T / I) \mid F T$ & دعوا و مشاجره(خانوادَىى، با & \multirow{6}{*}{ علت و انغيزه } \\
\hline & $(\Delta / \mu) \psi r$ & r & (ॅ) 1 . & مسائل عاطفى (جدايى از همسر، & \\
\hline & $(\Delta / 1) \& l$ & $(F / \Delta) Y l$ & $(\Delta / 9) \Gamma \cdot$ & مشكل روانى (افسردگى و ..) & \\
\hline & $(r / I) \Gamma \Delta$ & $(1 / 1) \Delta$ & $(\Delta / q) \mathrm{r}$. & اعتياد & \\
\hline & $(\Delta / \Lambda) F V$ & $(r / F) \|$ & $(1 \cdot / 4) \Psi \varepsilon$ & مشكل اقتصادى - مشى & \\
\hline & $(r \& / 9) r \mid \varphi$ & $(Y T / V) 1.9$ & $(\Psi Y / 9) 11$. & ساير موارد (افت تحصيلى و ...) & \\
\hline \multirow{6}{*}{$\begin{array}{c}\chi^{2}=r \bigvee / \backslash \Lambda r \\
\mathrm{df}=r \\
\mathrm{p}<\cdot / \cdot \cdot 1\end{array}$} & $(V T / \mathcal{L}) \Delta \Lambda Y$ & $(\vee 9 / 4)$ r६६ & $\left(\varepsilon \Delta / \varphi^{\prime}\right) \Gamma \mid \varepsilon$ & قرص ق & \multirow{6}{*}{ روشهاى مورد استفاده } \\
\hline & $(\Delta / \mu) F r$ & (T) 9 & $(1 \cdot / \mu) \mu F$ & حلق آويز كردن & \\
\hline & $(\mid r / 1) q V$ & $(1) / \Lambda) \Delta F$ & $(1 r / 1) F r$ & 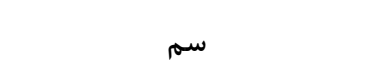 & \\
\hline & $(1 / V) \mid f$ & $(\cdot / 9)^{k}$ & (ए) 1 . & خود زنى با اشياء & \\
\hline & ( & $(\Delta / V) \Gamma G$ & $(\Lambda / T) Y V$ & ساير موارد & \\
\hline & $(1 / 9) 10$ & ---- & ---- & بدون ياسخ & \\
\hline
\end{tabular}

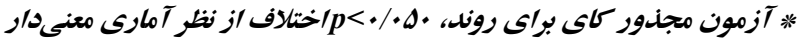

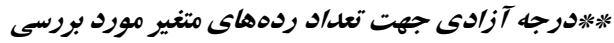


اختلاف از نظر آمارى معنى دار بود (ه • •|•P). شايعترين علت و انخيزه اقدام به خودكشى در دو گروه جنسى، دعوا و مشاجره بود. اما اين نسبت در زنان (• ( طور معنىدارى بيشتر از مردان (FF/I IF أF درصد ) بود

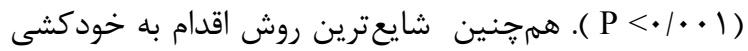
در هر دو جنس، استفاده از قرص بود و روش مورد استفاده در دو گروه اختلاف آمارى معنىدارى با يكديگر داشت $($ ( $)(p<\cdot 1)$

\section{بحث}

نتايج يزوهش حاضر بيانگر آن بود كه ميزان شيوع كلى خودكشى در اين شهرستان V9V در هر صد هزار نفر مى باشد. هم جنين ميزان شيوع خودكشى فرجام يافته (منجر به مرگ)

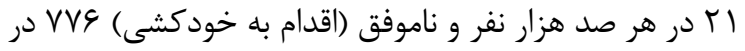
هر صد هزار نفر بود. در همين راستا ميزان بروز خودكشى و اقدام به آن در شهرستان لارستان، گَراش، بهار و استان خراسان رضوى به ترتيب هץ/T، سو/ه内، NV/D و

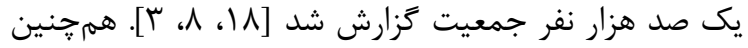
بر اساس مطالعات Daliri و همكاران ميزان بروز خودكشى در ايران طى سالهاى سوץ|-•^ץ|، ^ در صد هزار نفر بود. بيشترين ميزان بروز اقدام به خودكشى مربوط به منطقه ه (اصفهان، يزد، سمنان و قمم) II در صد هزار نفر و كمترين ميزان مربوط به منطقه 9 (جهار محال-بختيارى، كهَيلويه و بوير احمد، خوزستان) VV در صد هزار نفر بود. بيشترين ميزان بروز خودكشى فرجام يافته در كشور نيز مربوط به منطقه اقليمى ( (ايلام، لرستان، همدان، كردستان، كرمانشاه)
تحليل نتايج مطالعه حاضر براساس جنسيت نشان داد كه هرجند در دو گروه جنسى، بيشتر افراد اقدام كننده به خود كشى بين 19 تا ها سال سن داشتند؛ اما درصد بيشترى از مردان ( درصد) در اين گروه قرار گرفتند. از طرف ديگر گروه سنى

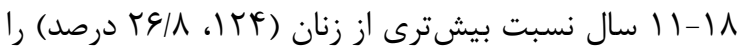
در مقايسه با مردان (9)، IV/V درصد) به خود اختصاص دادند و بر اساس آزمون كاى- دو اين تفاوتها معنىدار بود

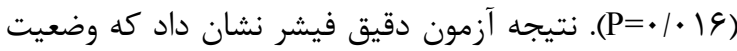
تأهل در دو گروه مردان و زنان اقدام كننده به خودكشى اختلاف آمارى معنى دارى داشت ( ( • • (p). بهطورى كه در

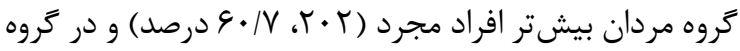
زنان بيشتر افراد متأهل (ا9r، \& \&/9 درصد) اقدام به خود كشى كرده بودند. مردان داراى شغل آزاد (r •ا، Fr

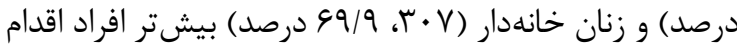
كننده به خودكشى را تشكيل دادند. بر اساس آزمون دقيق فيشر اين تفاوت از نظر آمارى معنى دارى بود ( ا | • P= P). در مطالعه حاضر مقايسه متغيرهاى سطح تحصيلات، محل سكونت، سابقه اختلال روانى و سابقه قبلى اقدام به خودكشى بر اساس دو جنس، تفاوت آمارى معنىدارى را نشان نداد $(\mathrm{P}>\cdot / \cdot \Delta)$ يافتهها بيان گر آن بود كه در گروه مردان بيشتر افراد (ع ا، ع/اسادرصد) در فصل بهار و در زروه زنان بيشتر افراد (ع\&\&)،

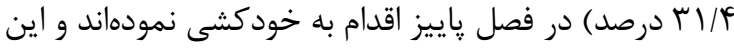


TFT بررسى إيدميولوزى خود كثى در شهرستان اسد آباد

يافتههاى مطالعه بيان كر آن بود كه اكثر افراد (به طور كلى و نيز در دو جنس) در گروه سنى ضس - 19 سال و در رتبه بعدى در گروه سنى 1|-1|| سال قرار داشتند. اما زنان در مقايسه با مردان، در سن يايينترى اقدام به خودكشى مى كردند. در مطالعه Faridpak و همكاران در مشهد گروه سنى Shaker ، و همكاران در تهران گروه سنى زير • • سال و Vahdati و همكاران در تبريز گروه سنى •r-آ سال، اكثريت افراد را به خود اختصاص دادند [^r، צr، זr]. Khadem Rezaiyan اقدام كننده به خودكشى در رده سنى إ إل سال و سيس

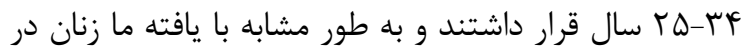
سن קايينتر و مردان در سن بالاتر اقدام به خودكشى كرده بودند [^]. وقوع بيشتر خودكشى در اين دامنه سنى مىتواند با بحرانهاى روحى و روانى دوره جوانى، مسائل اجتماعى، فرهنگى، اقتصادى و خانوداگى (ازدواج و مشكلات زناشويى) مرتبط باشد. از طرف ديخر سن يايينتر خودكشى براى خانمها و سن بالاتر براى آقايان، مىتواند نشان دهنده حساسيت هركدام از اين دو جنس در دامنه سنى خاص باشد. نتايج يزوهش نشان داد كه ميزان شيوع خود كشى در افراد مجرد بيشتر است. اما در مقايسه بين دو جنس، مردان مجرد و زنان متأهل بيشترين موارد اقدام به خودكشى را به خود اختصاص دادند. همسو با يافته ما تعدادى از مطالعات نيز بيشترين فراوانى موارد خود كشى را در افراد مجرد ذكر كردند

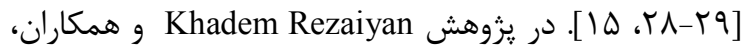
زنان متأهل با درصد بيشترى نسبت به مردان متأهل اقدام
/ I د/ در صد هزار نفر و كمترين ميزان مربوط به منطقه اقليمى ه (اصفهان، يزد، سمنان و قم) r/A در صد هزار نفر

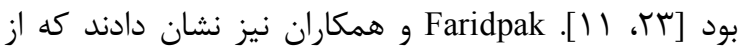
FrDF مورد اقدام به خود كشى و خود كشى كامل در سالهاى

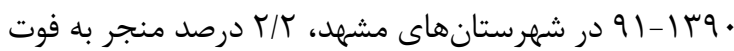
شده بود [YF]. بالاتر بودن ميزان شيوع خودكشى در مطالعه حاضر مىتواند به دليل عوامل اقليمى، فرهنكى، اقتصادى و شرايط خاص شهرستان باشد. همرجنين در مناطق مختلف كشور عوامل جغرافيايى و جوى مىتوانند بر ميزان بروز خود كشى مؤثر باشند.

در مطالعه حاضر زنان اكثريت افراد اقدام كننده به خودكشى را تشكيل دادند. همرجنين ميزان شيوع خودكشى در زنان بيشتر از مردان بود. به طور مشابه اين يافته توسط

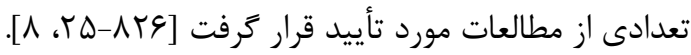
همجهنين Faridpak و همكاران نشان دادند كه V// درصد از كل موارد اقدام به خودكشى مربوط به زنان بود؛ در حالى كه بيش از • V درصد موارد خودكشى كامل در بين مردان روى داده بود [YF] برخلاف يافته ما، در ساير مطالعات اكثريت

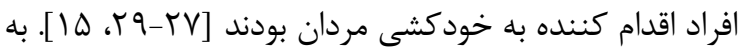
نظر مىرسد كه زنان به دلايل مختلف مثل مسائل عاطفى، حساسيت و آسيبيذيرى بيشترى در مواجهه با سختىها و مشكلات و جلب توجه ديگران به خود، استرس و بحرانهاى بعد از ازدواج، خانهدار بودن و در نتيجه فقدان استقلال مالى و اجتماعى بيش از مردان در معرض خطر خودكشى قرار دارند. 
ديخر از مطالعات، افراد داراى مشاغل آزاد اكثر موارد خودكشى را به خود اختصاص دادند [1/، IN]. همرجنين Yaraghi و همكاران بين ساعت كارى خانمهاى شاغل و اقدام به خودكشى به ارتباط مثبتى دست يافتند [1]. دليل احتمالى براى اين يافته مىتواند مربوط به فقر اقتصادى و اجتماعى ناشى از فقدان اشتغال و متعاقباً افزايش خطر خودكشى باشد. بر اساس نتايج يزوهش حاضر، ميزان شيوع خودكشى در افراد ساكن در شهر بيشتر بود. به طور مشابه در نتايج برخى از مطالعات، اكثراً افراد اقدام كننده به خودكشى شهرنشين بودند

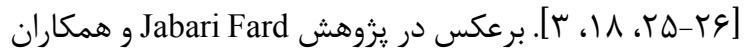
اكثراً افراد اقدام كننده به خودكشى در شهرستان لردگان را افراد ساكنين روستاها تشكيل دادند [سب]. نتايج يزوهش نشان داد كه اكثريت افراد (دو سوم) اولين تجربه اقدام به خودكشى را داشتند. Gorgi و همكاران بلطور مشابهى بيشترين موارد خودكشى و اقدام به آن را در افراد بدون سابقه خودكشى در فرد و خانواده كزارش كردند [11]]. اما در مطالعه Yaraghi و همكاران سابقه مثبت خودكشى قبلى در خانمهاى شاغل و خانهار مشاهده شد [ []. همجنين Torkashvand در افراد با سابقه مسموميت قبلى به طور معنىدارى بيشتر بود [ro]. مطابق كزارش سازمان بهداشت جهانى سابقه قبلى خودكشى، عامل خطر مهمى براى بروز مجدد خودكشى مى باشد [§]. بنابراين مى توان با ارجاع افرادى كه براى اولين بار مرتكب خودكشى شدهاند به مراكز روانشناسى و مشاورهاى و حمايت از آنان، خطر خودكشى مجدد را كاهش داد. يافتهها
به خودكشى كرده بودند [^]. برخلاف يافته ما، Khadem Rezaiyan و همكاران و Yaraghi و همكاران در مطالعات خود نشان دادند كه خودكشى در افراد متأهل بيشتر بود [1، []. علت يافته ما مىتواند مربوط به داشتن آرامش روانى، حمايت عاطفى و مالى و متعاقباً كاهش خودكشى به واسطه تأهل باشد.

يافتهها بيانكر آن بود كه ميزان شيوع خودكشى در افراد داراى مدرك متوسطه بيشتر از بقيه كَروهاى تحصيلى است. در همين راستا نتايج برخى از مطالعات تأييد كننده موارد بيشتر خودكشى در افراد با تحصيلات راهنمايى/ متوسطه بود

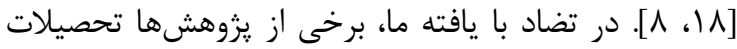
هايين و بى سوادى را به عنوان عامل خطر مرتبط با اقدام به خودكشى و مرك ناشى از آن معرفى كردند [זr-••r]. به نظر مىرسد كه تحصيلات بالاتر مىتواند بهرهگيرى فرد از شيوه هاى مقابلهاى را ارتقاء داده و در بحرانهاى روزمره به كمك

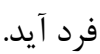
در مطالعه حاضر ميزان شيوع خودكشى در افراد غير شاغل بيشتر از افراد شاغل بود. اما در دو جنس، مردان داراى شغل آزاد و زنان خانهدار بيشتر افراد اقدام كننده به خودكشى را تشكيل دادند. در همين راستا تعدادى از مطالعات داخلى و خارجى در نتايج خود، عدم استخدام و بيكارى و خانهدار بودن را به عنوان عوامل خطر مرتبط با مرك ناشى از خودكشى ذكر

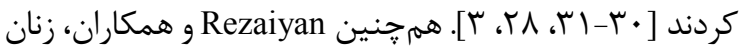
خانهدار و مردان داراى مشاغل آزاد را به عنوان اكثر افراد اقدام كننده به خودكشى معرفى كردند [^]. اما در نتايج تعدادى 
TFF بررسى إيدميولوزى خود كثى در شهرستان اسد آباد

و Jayanathi و همكاران در نتايج خود، به مشكلات بين فردى مانند مشاجرههاى زناشويى و ساير اختلافات خانوادگى به عنوان رايجترين دلايل ززارش شده براى خودكشى و اقدام به

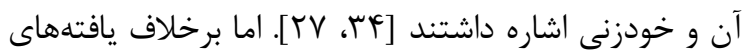
ما برخى مطالعات، بيمارىهاى روانى را مهمترين دليل اقدام

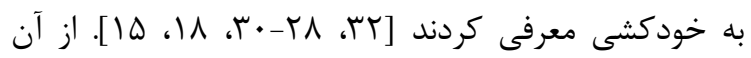
جايى كه مشاجرههاى خانوادگى به عنوان يك عامل خطرزاى مهمم قلمداد شده است، آموزش مهارتهاى زندكى با تأكيد بر آموزش حل مشكل، شناسايى و مداخله علمى براى حل مشكلات خانوادگى مىتواند كارگشا باشد. بررسى روشهاى مورد استفاده براى اقدام به خودكشى در مطالعه حاضر نشان داد كه به طور كلى و در دو جنس، استفاده از قرص بيشترين و خودزنى با اشياء كمترين روشهاى مورد استفاده بودند. اما اين نسبت در زنان بيشتر از مردان بود. همسو با يافته ما، تعدادى از مطالعات شايعترين روش

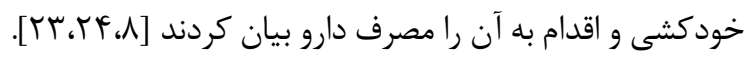
برعكس، در مطالعه Yaraghi و همكاران شايعترين روش خودكشى در هر دو زروه خانمهاى خانهدار و شاغل، مسموميت عمدى بود [1]. همجنين Armitage و همكاران نشان دادند كه مسموميت (خوردن سم) رايجترين روش براى خودكشى بود [بr]]. به نظر مىرسد كه دسترسى راحت به دارو و تهيه داروى بدون نسخه از داروخانهها، وسيله لازم براى خودكشى در افراد مستعد را فراهم كرده و متعاقباً خطر خودكشى را افزايش داده است. محدوديتهاى مطالعه حاضر شامل عدم اطلاع از دقت و صحت جمع آورى دادهها و ثبت
بيانگر آن بود كه كمتر از يك درصد افراد اقدام كننده به خود كشى، سابقه اختلال روانيزشكى داشتند. در همين راستا در يروهش Gorgi و همكاران بيشترين موارد اقدام به خود كشى در افراد فاقد سابقه بيمارى جسمى و روانى مشاهده شد [11]. اما در برخى ديكر از مطالعات داخلى، خودكشى با

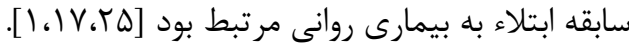
در مطالعه حاضر فصل ياييز به عنوان فصل داراى بيشترين ميزان شيوع خودكشى شناخته شد. در دو جنس نيز، زنان بيشتر در فصل ياييز و مردان در فصل بهار اقدام به خودكشى كرده بودند. به طور مشابه اين يافته توسط برخى مطالعات تأييد شد [11 ، ،س世]. اما برخلاف يافته ما، Babanejad و همكاران فروردين ماه و فصل بهار را در مقايسه با متغيرهاى مشابه خود، داراى بيشترين فراوانى موارد خودكشى ناشى از اختلالات روانى معرفى كردند [بr]. در مطالعات Shaker و همكاران و Rezayian و همكاران، در فصل زمستان بيشترين موارد اقدام به خود كشى صورت گرفته بود [^r، ^]. به نظر مىرسد عاملهاى مرتبط با اين يافته، تفاوتهاى جغرافيايى و ساعات تماس با نور خورشيد باشند. اما بررسى و تحقيقات بيشترى در اين زمينه لازم است. نتايج يزوهش بيان دعوا و مشاجره خانوادگى بيشترين و اعتياد كمترين انگيزه افراد براى اقدام به خودكشى بود. اما اين نسبت در زنان بيشتر از مردان بود. در همين راستا تعدادى از مطالعات شايعترين علت خودكشى و اقدام به آن را مشكلات و اختلافات خانوادگى

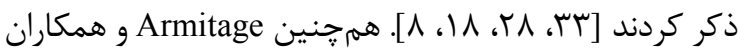


خودكشى در افراد بود. بنابراين مىتوان با اجراى برنامههاى مداخلهاى متناسب مانند تأسيس مراكز مشاوره خانواده و آموزش كافى به خانوادهها و گروههاى آسيب يذير، كاهش دسترسى به وسايل خودكشى و آموزش كاركنان بهداشتى در ارزيابى و مديريت رفتارهاى خودكشى در جهت پيشخيرى از خود كشى كام برداشت تشكر و قدردانى

اين مقاله از طرح تحقيقاتى مصوب در شوراى يزوهشى دانشعاه

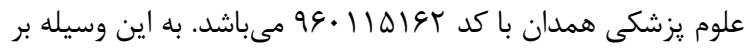

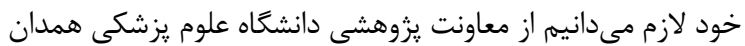

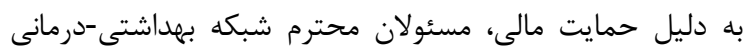

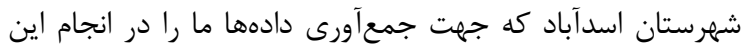
مطالعه يارى رساندند، تشكر و قدردانى نماييمه
آنها در فرمهاى مخصوص خودكشى و عدم دسترسى به كل نمونهها به دليل ثبت نشدن يا مراجعه نكردن فرد به مراكز درمانى بود. اين دو عامل سبب مىشوند كه آمار دقيقى از ميزان شيوع خودكشى و عوامل مرتبط با آن به ثبت نرسد. بنابراين جهت برطرف شدن تأثير اين عوامل، ييشنهاد مىشود كه مطالعات آتى به صورت آيندهنكر و تحليلى تكميلى (طولى) براى شناسايى عوامل مرتبط با اقدام به خودكشى در سطح

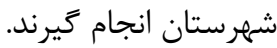

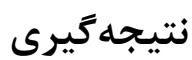

يافتههاى يروهش حاضر نشان داد كه مشاجرات خانوادكى مهمترين علت خودكشى و استفاده از قرص رايجترين شيوه

\section{References}

[1] Yaraghi A, Eizadi Mood N, Akoochekian S, Naderolasli M, Ahmadloo H, Dorooshi G. Comparison of Factors Associated with Suicide Among Employed Women and Housewives. $J$ Forensic Med 2014; 20(2): 47 -53. [Farsi]

[2] Azizi M, Rahmati R. A Review of suicide and its causes. Paramedical Sciences and Military Health. Fall and winter 2014; 9(2). [Farsi]
[3] Moradi AR, Moradi R, Mostafavi E. A survey of the rate and effective factors on suicide in Bahar. JBS 2012; 10(1): 50-8. [Farsi]

[4] Cha CB, Franz PJ, Guzman EM, Glenn CR, Kleiman EM, Nock MK. Annual Research Review: Suicide among youth -epidemiology, (potential) etiology, and treatment. Journal of Child Psychology and Psychiatry 2018; 59(4): $460-82$. 


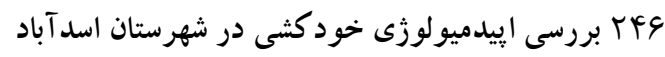

[5] Vojoudi B, Hashemi T, Abdolpour G, Mashinchi Abbasi N. Predicting suicide ideation based on identity styles and coping strategies. Contemporary psychology 2015; 10(1): 47-56. [Farsi]

[6] https://www.who.int/news-room/fact-sheets/ detail/suicide .2 September 2019.

[7] Mirhashemi S, Kalantar Motamedi $\mathrm{MH}$, Mirhashemi AH, Taghipour H, Danial Z. Suicide in Iran. Wwwthelancetcom 2016; 387: 29. [Farsi]

[8] Khadem Rezaiyan M, Jarahi L, Moharreri F, Afshari R, Motamedalshariati SM, Okhravi N, et al. Epidemiology of suicide attempts in Khorasan razavi province, 2014-2015. IJ E summer 2017; 13(2): 128-35. [Farsi]

[9] Simbar M, Golezar S, Alizadeh S, Hajifoghaha M. Suicide Risk Factors in Adolescents Worldwide: A Narrative Review. JRUMS 2017; 16(12): 1153-68. [Farsi]

[10] Ribeiro JD, Franklin JC, Fox KR, Bentley KH, Kleiman EM, Chang BP, et al. Self-injurious thoughts and behaviors as risk factors for future suicide ideation, attempts, and death: a metaanalysis of longitudinal studies. Psychological Medicine 2016; 46: 225-36.

[11] Daliri S, Bazyar J, Sayehmiri K, Delpisheh A, Sayehmiri F. The incidence rates of suicide attempts and successful suicides in seven climatic conditions in Iran from 2001 to 2014: a systematic review and meta-analysis. Scientific SJKU Jan-Feb 2017; 21: 1-15. [Farsi]

[12] Khani Pour H, Mouhammad Khani P, Jafari F, Mobarram A. Predictors of suicide in male prisoners with substance abuse and dependence : protective factors and risk factors. Journal of forensic medicine fall 2012 and spring 2013; 19(4,1): 205-14. [Farsi]

[13] Naghibi SA, Azizpoor M, Ashari S, Hosseini Sh, Alizadeh A. The study of the relation between suicidal thoughts and religious belief in patients under methadone maintenance treatment (MMT) of Sari in 2013. Religion \& Health 2014; 2(1): 18. [Farsi]

[14] Thompson MP, Swartout K. Epidemiology of Suicide Attempts among Youth Transitioning to 
Adulthood. J Youth Adolescence 2018; 47: 807-

17.

[15] Bakhtar M, Rezaeian M. The Prevalence of Suicide Thoughts and Attempted Suicide Plus Their Risk Factors Among Iranian Students: A Systematic Review Study. JRUMS 2017; 15(10): 1061-76. [Farsi]

[16] Nazarzadeh M, Bidel Z, Ayubi E, Soori H, Sayehmiri K. Factors Related to Suicide Attempt in Iran:A systematic Review and Meta-Analysis. Hakim Research Journal 2013; 15(4): 352- 63. [Farsi]

[17] Shakeri A, Jafari zadeh F. Study-related causes Suicides in Fars Province. J Mazandaran Univ Med Sci 2012; 22(97): 271-5. [Farsi]

[18] Gorgi Z, Sheikh Fathollahi M, Askarizadeh MK, Rezaeian M. Epidemiology of Suicide and Attempted Suicide in Larestan and Gerash During 2008 to 2012. JRUMS 2014; 13(5): 597608. [Farsi]

[19] Monsef Kasmaei V, Asadi P, Maleki Ziabari M. A Demographic study of suicide methods in the patients aided by emergency Paramedics Guilan. Jof Guilan university of medical sciences 2013; 22(87): 31-7. [Farsi]

[20] Fadaiian A, Khoram abady Y, http://www.civilica.com/Paper-ICCRT01ICCRT01_0378.html:1-8. Study the relationship between religiosity with a desire to thoughts of suicide in Ilam city. The international congress of culture and religious thought 2014. [Farsi]

[21] Hadavand Mirzaei H. The effect of texting to people who have committed suicide in their continued treatment in the city of Bandar Abbas in 2012-2013. University of Medical Sciences, Bandar Abbas 2013. [Farsi]

[22] Iran: Statistical center of Iran; 2019 [cited 2019]. Available from: https://www.amar.org.ir/english/Population-andHousing-Censuses.

[23] Daliri S, Bazyar J, Sayehmiri K, Delpisheh A, Sayehmiri F. Investigation of the Incidence rate of suicide in Iran During Years 2001-2014 A Systematic Review and Meta-analysis study. JSSU 2016; 24(9): 757- 68. [Farsi] 
L ب TH بررسى إيدميولوزى خود كثى در شهرستان اسدآباد

[24] Faridpak A, Nikakhtar Z, Mosa Farkhani E. An Epidemiologic Study of Suicide in Cities under Mashhad University of Medical Sciences Supervision. Journal of Student Research Committee Sabzevar University of Medical Sciences Beyhagh 2016; 21(36): 21-9. [Farsi]

[25] Torkashvand F, Sheikh Fathollahi M, Shamsi S, Kamali M, Rezaeian M. Evaluating the Pattern of Acute Poisoning in Cases Referred to the Emergency Department of Ali-ebn Abi Taleb Hospital of Rafsanjan from October 2013 to September 2014. JRUMS 2015; 14(4): 311-24. [Farsi]

[26] Vahdati SS, Moradi N, Ghadim Jh, Tajoddini S. Evaluation of suicide attempts with drug poisoning in north -west of Iran. Journal of Emergency practice and trauma 2015; 1(1): 1-2.

[27] Jayanthi R, Muralidharan RS, Gauthaman CS, Arun Kumar PP. An observational study on orally ingested poison cases in attempted suicide at toxicology unit of IMCU,Stanley medical college. SMJ 2015; 2(3): 12-3.
[28] Shaker SH, Hossieni Kasnaviyyeh MH, Basir ghafouri H, Tavakoli N, Yasinzadeh, M., Masoumi G, et al. Epidemiological survey of attempted suicide among patients admitted to hazrat rasoul hospital in Tehran 2007-2011. Ir J Forensic Med 2017; 23(1): 7-15. [Farsi]

[29] Zarenezhad M, Gorgi Z, Sheikh Fathollahi M, Gholamzadeh S, Ghadipasha M, Rezaeian M. A Survey of Epidemiology of Suicide in Fars Province in the south of Iran during 2003 to 2011. JRUMS 2015; 13(11): 1129-40. [Farsi]

[30]Crump C, Sundquist K, Sundquist J, Winkleby MA. Sociodemographic, psychiatric and somatic risk factors for suicide: a Swedish national cohort study. Psychological Medicine 2014; 44: 279-89.

[31] Pires M, Silva T, Pires dos Passos M, Sougey E, Filho O. Risk factors of suicide attempts by poisoning: review. Trends Psychiatry Psychother 2014; 36(2): 63-74.

[32] Babanejad M, Pourkaramkhan T, Delpisheh A, Khorshidi A, Asadollahi K, K. S. Epidemiological Investigation of Suicide due to 
Mental Disorders in Ilam Province during 19932009. SJIMU 2014; 22(5):104-13. [Farsi]

[33] Jabari Fard F, Ghari A, Yazd Khasti F, Masoudi S. The Epidemiology of suicide and related factors in the city of Lordegan from 2001-2011. Journal of Shahrekord University of Medical
Sciences J Shahrekord Univ Med Sci 2014;15(6):

75-86. [Farsi]

[34] Armitage CJ, Panagioti M, Abdul Rahim W, Rowe R, O’Connor RC. Completed suicides and self-harm in Malaysia: a systematic review. General Hospital Psychiatry 2015; 37: 153-65.. 


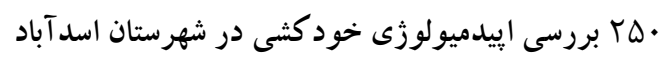

\title{
Epidemiological Study of Suicide in Asadabad City in 2011-2017: A Descriptive Study
}

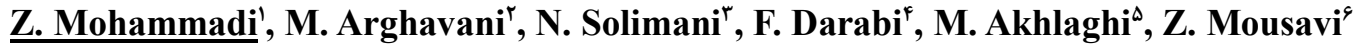

Received: 09/11/2019 Sent for Revision: 25/11/2019 Received Revised Manuscript: 19/04/2020 Accepted: 21/04/2020

Background and Objectives: Suicide is one of the biggest medical and social problems of the world. The present study was conducted with the aim of investigating the epidemiology of suicide in Asadabad city during 2011-2017. Materials and Methods: In this descriptive study, demographic and epidemiologic data of suicide attempts and complete suicide were extracted using special forms of suicide archived in the Asadabad Health Network during the years of 2011-2017. The data were analyzed using descriptive statistics.

Results: The overall prevalence of suicide was 797/100000 people (804 cases), the prevalence of successful suicide (death) 21/100000 people (21 cases) and unsuccessful 776/100000 people (n783). Women (934/100000 people, $\mathrm{n}=466)$, single people $(1548 / 100000$ people, $\mathrm{n}=374)$, persons with secondary degree $(3889 / 100000$ people, $n=258)$, unemployeds (790100000 people, $n=577)$, residents of the city $(792 / 100000$ people, $n=289)$ and season fall $(240 / 100000$ people, $n=243)$ had the highest prevalence of suicide. The most important reason for committing suicide was, family fights and disputes $(53.7 \%, \mathrm{n}=432)$ and the most common method was pill consumption $(72.4 \%, \mathrm{n}=582)$. Conclusion: Considering that the main cause of suicide is family disputes and the most common form of suicide is the use of pills; Suicide outbreaks can be reduced by implementing appropriate interventions, such as establishing family counseling centers and adequate education for vulnerable families and gro ups, as well as reducing access to suicide devices.

Key words: Epidemiology, Suicide attempt, Asadabad city

Funding: This study was funded by Hamadan University of Medical Sciences.

Conflict of interest: None declared.

Ethical approval: The Ethics Committee of Hamadan University of Medical Sciences approved the study (IR.UMSHA.REC.1396.3).

How to cite this article: Mohammadi Z, Arghavani M, Solimani N, Darabi F, Akhlaghi M, Mousavi Z. Epidemiological Study of Suicide in Asadabad City in 2011-2017: A Descriptive Study. J Rafsanjan Univ Med Sci 2020; 19 (3): 233-48. [Farsi]

\footnotetext{
1- Instructor, Dept. of Nursing, Hamadan University of Medical Sciences, Hamadan, Iran, Asadabad School of Medical Sciences, Asadabad, Iran, ORCID: 0000-0001-5210-2760

(Corresponding Author): Tel (081) 33132015, Fax: (081) 33132015, E-mail: ziba.mohammadi14@yahoo.com

2- Undergraduate Student of Nursing, Student Research Committee, Hamadan University of Medical Sciences, Hamadan, Iran, ORCID:0000-0002-3704-9989

3-Undergraduate Student of Nursing, Student Research Committee, Hamadan University of Medical Sciences, Hamadan, Iran ORCID: 0000-0002-1496-8464

4 Assistant Prof. of Health Education and Health Promotion, Dept. of Public Health, Asadabad School of Medical Sciences, Asadabad, Iran, ORCID: 0000-0002-4399-1460

5- PhD Student of Biostatistics, Faculty of Biostatistics, Isfahan University of Medical Sciences, Isfahan, Iran, ORCID:0000-0003-3371-4301

6- Instructor, Dept. of Nursing, Boroujerd School of Nursing, Lorestan University of Medical Sciences, Lorestan, Iran, ORCID: 0000-00021267-9837

دوره 19، شماره ب، سال 99"1

مجله دانشگاه علوم يزشكى رفسنجان
} 